DOI: https://doi.org/10.36910/6775-2524-0560-2021-44-01

УДК: 515.2

Ісмаілова Неллі Петрівна, д. т. н., професор

https://orcid.org/0000-0003-0181-4420

Могилянець Тетяна Михайлівна, здобувач

https://orcid.org/0000-0003-0362-9907

Військова академія, м. Одеса

\title{
МОДЕЛЮВАННЯ СПРЯЖЕНИХ КРИВОЛІНІЙНИХ ПОВЕРХОНЬ РІЖУЧОГО IНСТРУМЕНТУ
}

Ісмаілова Н. П., Могилянець Т.М. Моделювання спряжених криволінійних поверхонь ріжучого інструменту. Пропонуємо моделювання ріжучого інструменту 3 передачею даних 3 комп'ютера на верстат 3 числовим програмним управлінням.

Ключові слова: моделювання спряжених поверхонь, параметричний кінематичний гвинт, зубчасті колеса, ріжучий інструмент, конволютний гелікоїд.

Исмаилова Н.П., Могилянец Т.М. Моделирование сопряженных криволинейных поверхностей режущего инструмента. Предлагаем моделирования режущего инструмента с передачей данных с компьютера на станок с числовым программным управлением.

Ключевые слова: моделирование сопряженных поверхностей, параметрический кинематический винт, зубчатые колеса, режущий инструмент, конволютний геликоид.

N. Ismailova, T. Mohylianets. Modeling of mating curved surfaces of the cutting tool. We offer modeling of a cutting tool with data transfer from a computer to a machine with numerical control.

Key words: modeling of mating surfaces, parametric kinematic screw, gear wheels, cutting tool, convolute helicoid.

Постановка наукової проблеми. У роботі пропонується параметричне моделювання спряжених конволютних гелікоїдів на базі параметричного кінематичного гвинта, для практичного використання в проектуванні ріжучого інструменту. Моделювання ріжучого інструменту для обробки криволінійних поверхонь знаходить широке застосування при підвищенні продуктивності і точності інженерної праці. Це досягається автоматизацією розрахунково-графічних робіт при вирішенні широкого класу задач в області машинобудування, профілювання різального інструменту i зубчастого зачеплення.

Аналіз досліджень. Оскільки поверхні обробної деталі i ріжучого інструменту $\epsilon$ спряженими, то кожну з даних поверхонь можна уявити: як обвідної по відношенню до другої рухомий поверхні [1]. Комп'ютерне моделювання спряжених криволінійних поверхонь деталей в машинобудуванні складної форми вирішує проблему підвищення точності профілювання різального інструменту.

Вперше задачу формоутворення кінематичного гвинта розробили вчені Г.І. Апухтін, О.Ф. Ніколаєв. Характеристики даного гвинта у наукових та практичних роботах описувалися лише як плоскі зображення. Передумовами для створення способу моделювання конволютних гелікоїдів на базі параметричного кінематичного гвинта $\epsilon$ теорема професора Подкоритова А.М.[1]. Параметричний кінематичний гвинт - це просторове зображення трьох гвинтових рухів, 3 яких два $\epsilon$ гвинтовими, а третій - результуючим.

Основна частина. У роботі пропонується моделювання спряжених конволютних гелікоїдів на базі параметричного кінематичної гвинта, для практичного використання в проектуванні ріжучого інструменту із застосуванням комп'ютерних програм. Останнім часом параметричне моделювання стає все більш багатофункціональним інструментальним способом вирішення завдань практичної діяльності людини в різних областях народного господарства, науки і техніки. При цьому потреби практики вимагають створення нових, ефективних методів і їх інструментарій.

Вчені геометри вже давно намагаються оптимізувати процес створення універсальних графічних способів проектування ріжучих інструментів, де $\epsilon$, по суті, графічне зображення параметрів кінематичних пар.

Зміна, одного з яких призводить до зміни інших і відкриває можливість отримання форм деталей по наперед заданих параметрах. Одним 3 поширених методів формування поверхонь ріжучого інструменту є параметричне моделювання спряжених конволютних гелікоїдів, що дозволяє 
визначити кінематичні поверхні систем складних рухів, та дати аналіз впливу кожного параметра на профіль і конструктивні розміри, де легко можна виявити помилки профілювання складних профілів.

Моделювання ріжучих інструментів для обробки криволінійних поверхонь знаходить широке застосування при вирішенні підвищення продуктивності і точності інженерної праці. Це досягається автоматизацією розрахунково-графічних робіт при вирішенні широкого класу задач в області машинобудування, профілювання різального інструменту і зубчастого зачеплення. У цій області обгрунтовується необхідність створення проектування такого виду, яке задовольняє проектування параметричного моделювання ріжучого інструменту з передачею даних, 3 комп'ютера на верстат з числовим програмним управлінням.

Для визначення робочої поверхні ріжучого інструменту необхідно визначити умови спряження поверхонь гелікоїдів деталі і інструменту. Одним з основних параметрів, що визначає вид спряжених поверхонь, є характер відносного руху пари деталь-інструмент. Можливі два варіанти відносного руху: кочення без ковзання і кочення з ковзанням. При коченні без ковзання відносний рух твірної представляє обертальний рух доданий визначником [2]. При значенні 3 ковзанням відносний рух твірної представляє миттєвий гвинтовий рух [3]. Поставлену задачу вирішимо геометричним моделюванням конволютних гелікоїдів для практичного використання при проектуванні ріжучого інструменту і зубчастого зачеплення довільного профілю кінематичних пар. За допомогою комп'ютерних технологій розробимо геометричне моделювання криволінійної поверхні ріжучого інструменту на базі параметричного кінематичної гвинта [4,5].

Викладення основного матеріалу. Розглянемо побудову конволютного гелікоїда, заданого параметрами 3 діаграми параметричного кінематичного гвинта рис.1. Гвинтова лінія гелікоїда задана системою рівнянь (1):

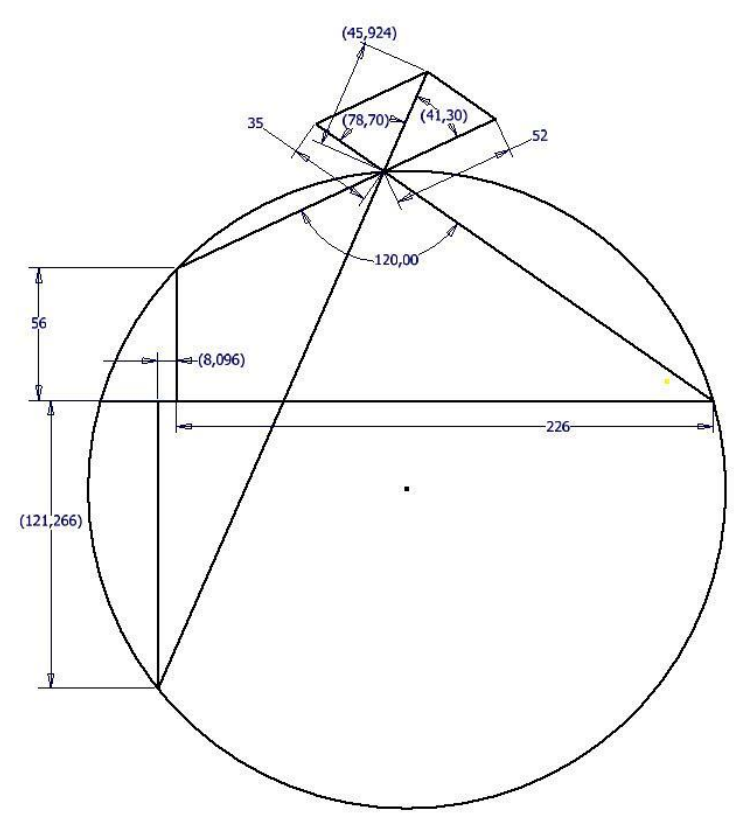

Рис.1 Діаграма параметричного кінематичного гвинта

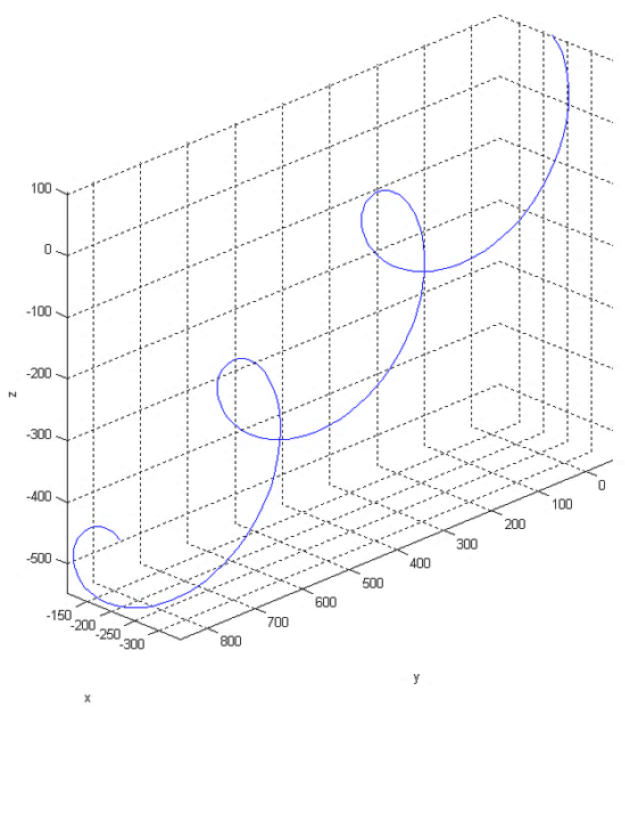

Рис.2 Тривимірне представлення криволінійної лінії гелікоїда 


$$
\left\{\begin{array}{c}
X=\sqrt{b^{2}+\frac{\omega_{A}^{2} \cdot \sin ^{2} \beta}{\cos ^{2} \alpha}} \cdot \cos \varphi-e ; \\
Y=\sqrt{b^{2}+\frac{\omega_{A}^{2} \cdot \sin ^{2} \beta}{\cos ^{2} \alpha}} \cdot \sin \varphi \cdot \cos \theta+\left[p \cdot \varphi+\frac{\omega_{A} \cdot \cos \beta}{\cos \alpha}\right] \cdot \sin \theta \\
Z=\sqrt{b^{2}+\frac{\omega_{A}^{2} \cdot \sin ^{2} \beta}{\cos ^{2} \alpha}} \cdot \sin \varphi \cdot \sin \theta+\left[p \cdot \varphi+\frac{\omega_{A} \cdot \cos \beta}{\cos \alpha}\right] \cdot \cos \theta
\end{array}\right.
$$

3 діаграми гвинта (рис.1) і рівнянь (1) отримаємо наступні значення параметрів:

$$
\begin{gathered}
\alpha=78.7^{\circ} ; \beta=41.3^{\circ} ; \theta=120^{\circ} ; \\
b=8.096 \text { мм; } \omega_{A}=35 ; \\
e=226 \text { мм; } p=56 \text { мм. } \\
\text { приймемо значення } \\
\varphi=\left[0: \frac{\pi}{30}: 10 \pi\right] .
\end{gathered}
$$

Визначена по заданим параметрам гвинтова лінія гелікоїда (рис. 2).

Застосування сучасних комп'ютерних технологій в науково-дослідній діяльності економить багато часу і збільшує точність проектування, дозволяє отримати візуалізацію необхідних процесів та побудов [6,7]. Для того, щоб досягти точності побудови криволінійних конволютних поверхонь, визначаємо сім'ю спряжених аксоїдів на базі просторового параметричного кінематичного гвинта. При побудові визначення точок контакту характеристик застосовуємо параметричний кінематичний гвинт графоаналітичним методом. Апроксимуючи точки контакту ліній сім’ї гелікоїдів, визначаємо криволінійну поверхню гелікоїда.

Розглянемо ще одну систему рівнянь (2) для побудови сім'ї криволінійної поверхні гелікоїда:

$$
\left\{\begin{array}{c}
X=b \cdot \sec \xi \cdot \cos (\xi+v)-e \\
Y=b \cdot \sec \xi \cdot \sin (\xi+v) \cdot \cos \theta+(b \cdot \operatorname{ctg} \beta \cdot \operatorname{ctg} \xi+p \cdot v) \cdot \sin \theta \\
Z=b \cdot \sec \xi \cdot \sin (\xi+v) \cdot \sin \theta+(b \cdot \operatorname{ctg} \beta \cdot \operatorname{ctg} \xi+p \cdot v) \cdot \cos \theta
\end{array}\right.
$$

Приймемо значення $v=\left[0: \frac{\pi}{30}: 6 \pi\right]$.

Будуємо криволінійну поверхню 3 сімейства криволінійних ліній конволютного гелікоїда за допомогою діаграмам параметричного кінематичного гвинта.

3 сімейства діаграм 1,2 (рис. 3 ) визначимо значення кута $\alpha, a$ і обчислимо значення $b, \beta, \omega_{\mathrm{A}}$,

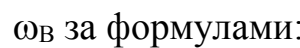

$$
\begin{gathered}
\omega_{A}=\frac{\omega_{m} \cdot \sin \beta}{\sin (90-\theta)} ; \omega_{B}=\frac{\omega_{m} \cdot \sin \alpha}{\sin (90-\theta)} ; \\
\beta=\theta-\alpha ; \\
b=e-a ; \\
a=\left\{\begin{array}{cccccc}
13.089 & 24.966 & 33.987 & 45.452 & 65.917 & 77.725 \\
102.107 & 109.848 & 132.581 & 147.417 & 173.118 & 198.033
\end{array}\right\}
\end{gathered}
$$



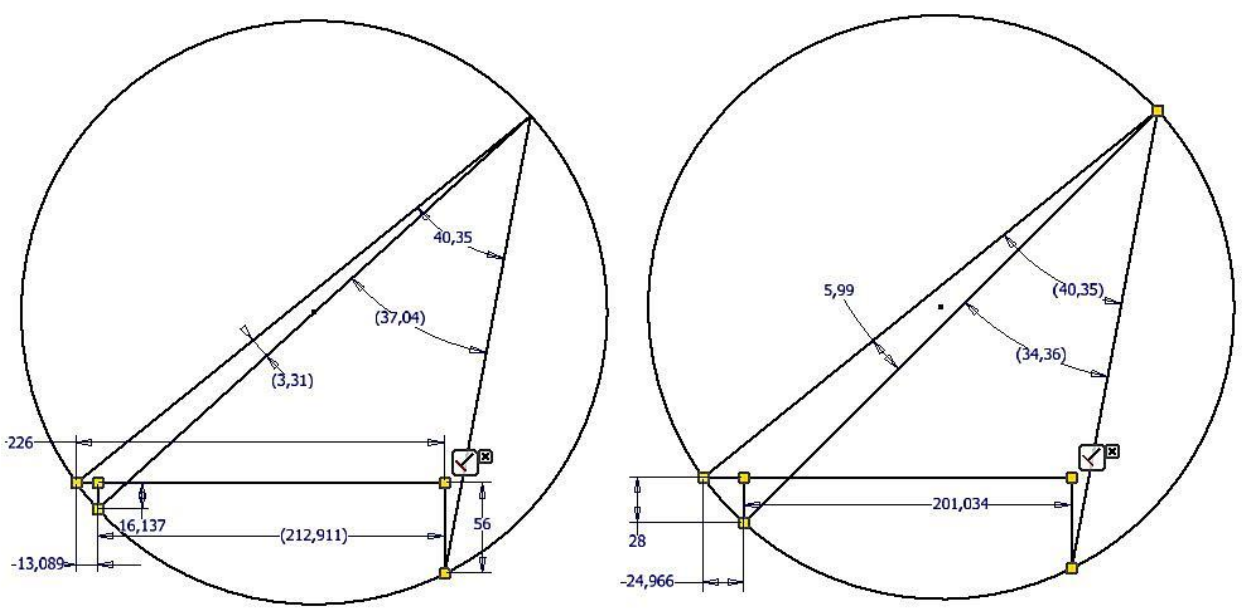

Рис. 3 Сімейство параметричного кінематичного гвинта

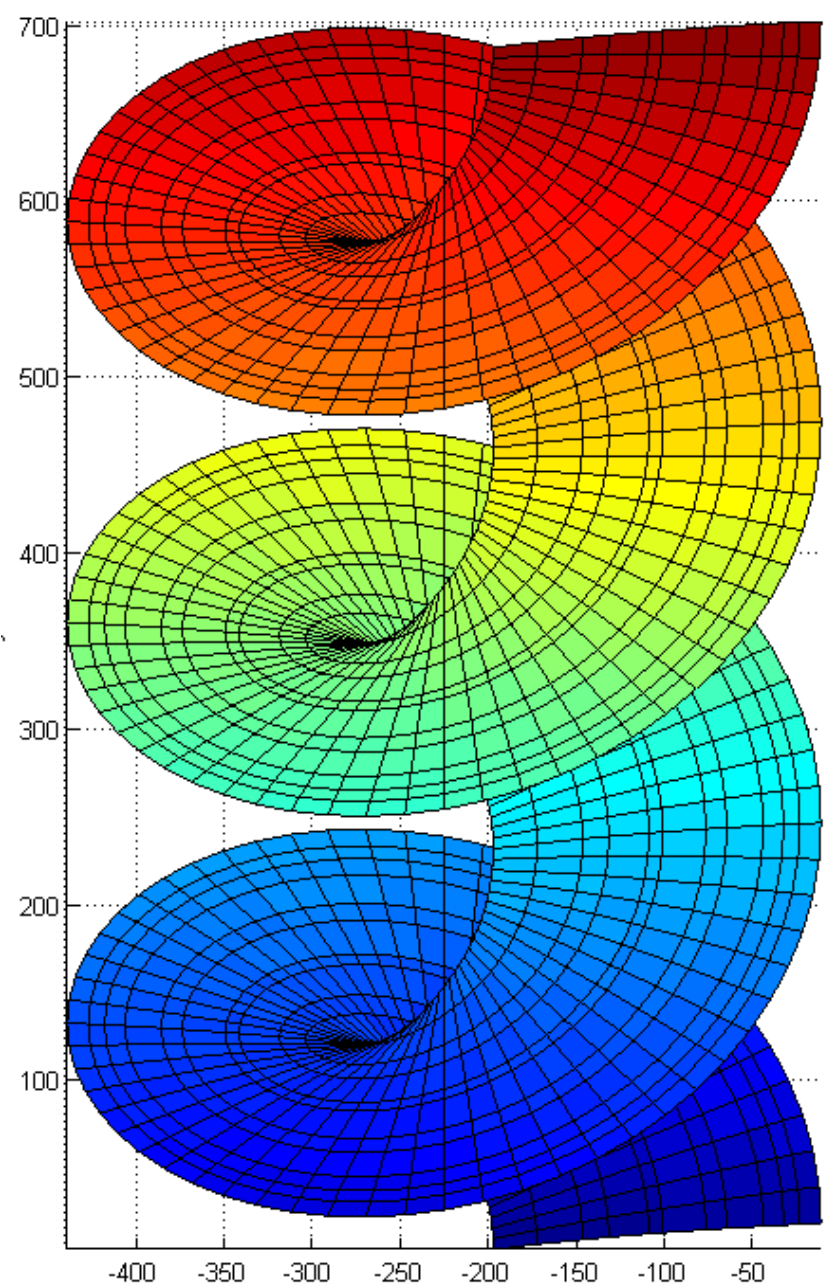

Рис. 4 Криволінійна поверхня конволютного гелікоїда

Результат запроектованої криволінійної поверхні конволютного гелікоїда на базі параметричного кінематичного гвинта представлено на рис. 4.

Графічний наочний метод дає можливість простими графічними прийомами визначити форму і розміри твірної криволінійної поверхні гелікоїда та збільшує точність проектування $\mathrm{i}$ дозволяє отримати візуалізацію необхідних процесів, або побудов (рис. 4). 
На рис. 4, отримано криволінійну поверхню конволютного гелікоїда яку в подальшому ми можемо використовувати для профілювання гвинтового ріжучого інструменту і криволінійного зубчастого зачеплення.

Використання в раніше отриманих залежностях, знову виведений параметр:

$$
\xi=\operatorname{arctg} \frac{\omega_{A} \cdot \sin \beta}{b \cdot \cos \alpha}
$$

Який дає можливість вирішити проблему по профілізації конусних поверхонь ріжучого інструменту і зубчастого зачеплення.

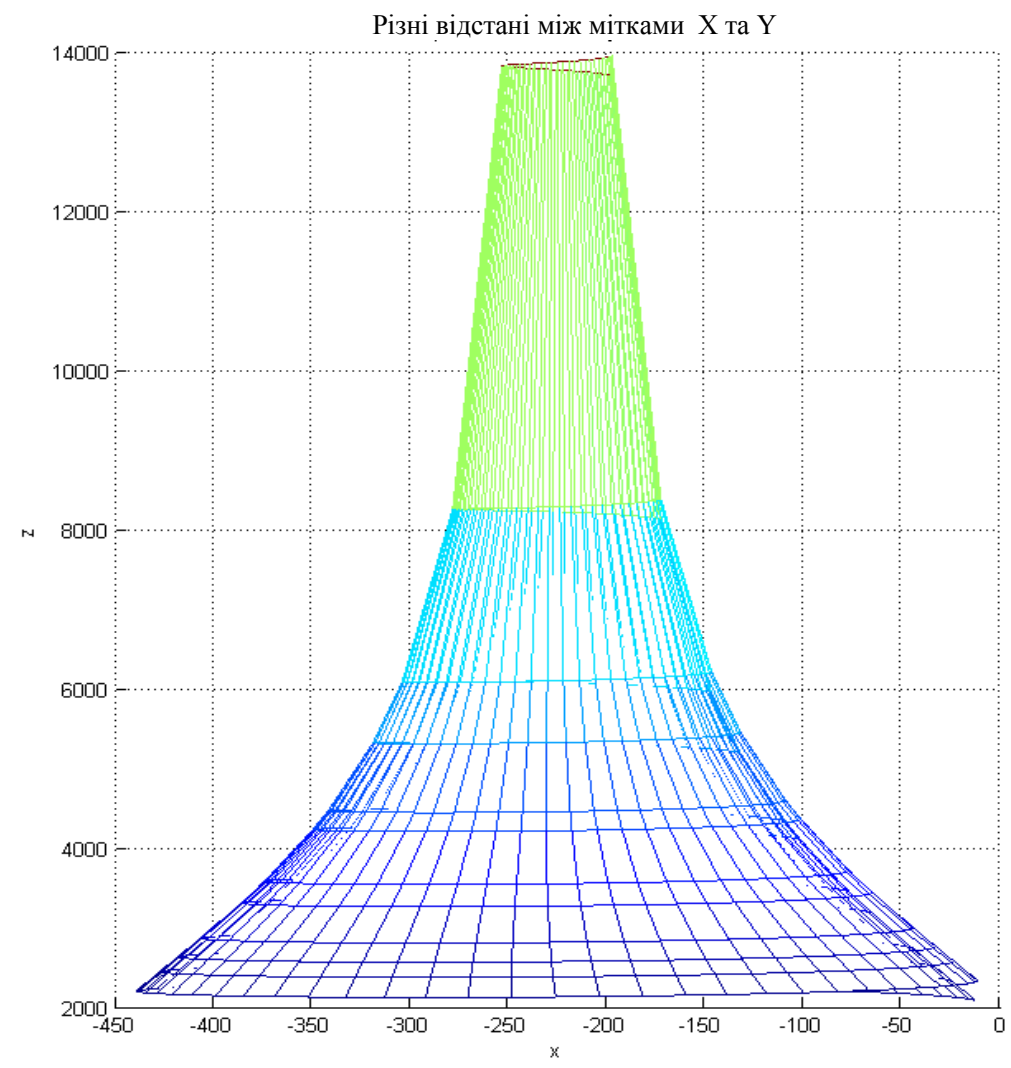

Рис. 5 Конусна криволінійна поверхня

Просторове визначення точок контакту може бути реалізовано на виробництві із застосуванням поширених сучасних персональних обчислювальних машин за умови достатнього рівня підготовки фахівця, який виконує моделювання.

Запропонований спосіб моделювання конволютного гелікоїда, на базі параметричного кінематичного гвинта, підвищує точність в проектуванні профілю ріжучого інструменту та зубчастого зачеплення. У цей час, практично всі проектні рішення виконуються за допомогою САПР. Це дозволяє істотно скоротити час на проектування. Але не завжди за допомогою стандартних засобів комп'ютерного моделювання можна вирішити поставлене завдання.

Розроблене моделювання спряжених конволютних гелікоїдів на базі параметричного кінематичної гвинта за допомогою комп'ютерного моделювання дозволяє вирішить складні завдання конструювання спряжених поверхонь, підвищити точність і продуктивність інженерної праці та створювати конкуренто-здатні вироби в машинобудуванні, літакобудуванні, кораблебудуванні.

Висновки та перспективи подальшого дослідження. Виконано конкретні розрахунки параметричного моделювання спряжених криволінійних поверхонь конволютного гелікоїда 3 подальшим застосуванням для профілювання різального інструменту i кінематичних пар. Запропоновано моделювання спряжених криволінійних гелікоїдів з передачею даних 3 комп'ютера на верстат з числовим програмним управлінням. 


\section{Список бібліографічного опису.}

1. Подкорітов А. М., Ісмаїлова Н. П. Теоретичні основи спряжених квазігравітаційних поверхонь, що виключають інтерференцію: монографія. Херсон: ФОП Грін Д. С., 2016. - 330 с.

2. Ісмаїлова Н.П. Квазігвинтові поверхні з точковим контактом. Прикладна геометрія та інженерна графіка. Матеріали. Таврійська державна агротехнічна академія. Vip. 4 т.35. - Мелітополь, 2007. - C.156-159.

3. Ісмаілова Н. П. Твердотільне моделювання спряжених поверхонь на базі параметричного кінематичного гвинта [Текст] /Ісмаілова Н. П. Комп’ютерно-інтегровані технології: освіта, наука, виробництво. - Луцьк, 2015. - С. 69-74.

4. N.Ismailova, V. Bogach, B. Lebedev «Development of a technique for the geometrical modeling of conjugated surfaces when determining the geometrical parameters of an engagement surface contact in kinematic pairs» eastern-european journal of enterprise technologies - Харків: Технологічний центр. - 2020, № 1/4(106). - С. 17-22.

5. Подкоритов А.Н., Исмаилова Н.П., Дюкре Л.Г. Метод формирования сопряженных винтовых нелинейчатых поверхностей семейством огибающих геликоидов. Геометричне та комп'ютерне моделювання. - Вип..17. ХДУХТ. - Харків, 2007. - С.12-15.

6. Ісмаілова Н.П., Трушков Г.В. Геометричне моделювання просторового параметричного кінематичного гвинта/ Комп'ютерно-інтегровані технології: освіта, наука, виробництво. Луцький національний технічний університет. Науковий журнал. №30-31 2018. Луцк - 2018. С. 187-195

7. Ісмаілова Н.П., Єлісєєв І.П. Моделювання спряжених кінематичних поверхонь за допомогою метода гвинтового перетворення в системе MATLAB /Комп'ютерно-інтегровані технології: освіта, наука, виробництво. Луцький національний технічний університет. Науковий журнал. №37 2019. Луцк - 2019. С. 66-71.

\section{References}

1. Podkoritov A. M., Ismailova N. P. Theoretical foundations of conjugate quasigravitory surfaces that exclude interference: a monograph. Kherson: FOP Grin D. C., 2016. - 330 s. \{in Ukrainian\}.

2. Ismailova NP Solid state modeling of conjugate surfaces based on parametric kinematic screw [Text] / Ismailova NP Computer-integrated technologies: education, science, production. Lutsk, 2015, pp. 69-74.

3. Ismailova N.P. Conjugated surfaces with point contact. Applied Geometry and Engineering Graphics. Proceedings. Tavria State Agrotechnical Academy. Vip. 4 т.35. - Melitopol, 2007. - S.156-159. \{in Ukrainian\}.

4. N.Ismailova, V. Bogach, B. Lebedev «Development of a technique for the geometrical modeling of conjugated surfaces when determining the geometrical parameters of an engagement surface contact in kinematic pairs» eastern-european journal of enterprise technologies - Харків: Технологічний центр. - 2020, № 1/4(106). - C. 17-22.

5. Podkoritov AN, Ismailova NP, Ducret LG Method of forming conjugate helical nonlinear surfaces by a family of envelope helicoids. Geometric and computer modeling. - Issue 17. - CDHD. - Kharkiv, 2007. - P.12-15.

6. Ismailova NP, Trushkov GV Geometric modeling of spatial parametric kinematic screw /Computer-integrated technologies: education, science, production. Lutsk National Technical University. Scientific journal. №30-31 2018. Lutsk - 2018. P. 187-195

7. Ismailova NP, I. Yelisyeyev, Model of conjugated kinematic surfaces on top of the helical rebuild method in the MATLAB system/ Computer-integrated technologies: education, science, production. Lutsk National Technical University.Scientific journal. №37 2019. Lutsk - 2019. P. 66-71. 